Document downloaded from:

http://hdl.handle.net/10251/148870

This paper must be cited as:

Broatch, A.; Margot, X.; Novella Rosa, R.; Gómez-Soriano, J. (2017). Impact of the injector design on the combustion noise of gasoline partially premixed combustion in a 2-stroke engine. Applied Thermal Engineering. 119:530-540.

https://doi.org/10.1016/j.applthermaleng.2017.03.081

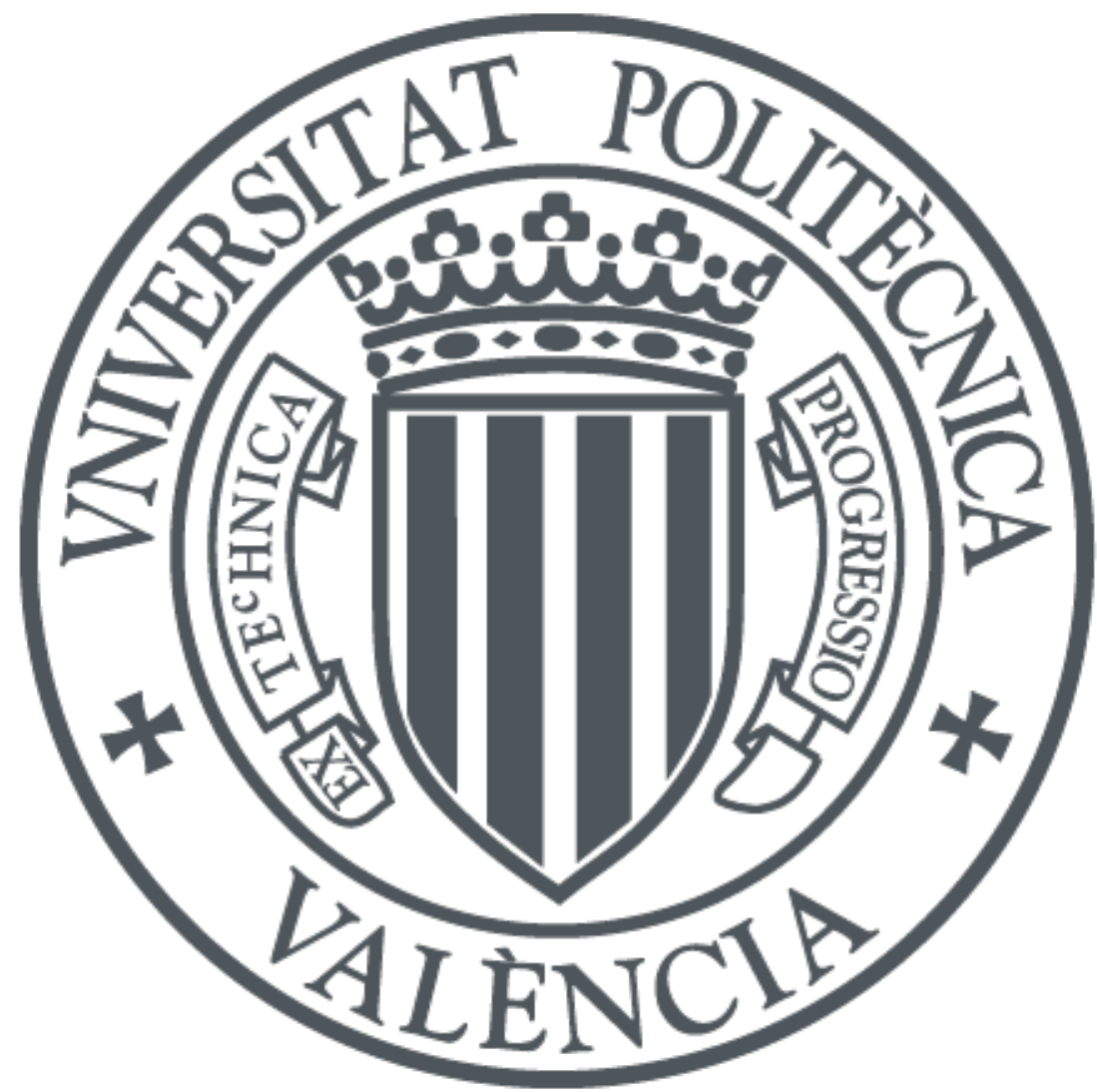

The final publication is available at

https://doi.org/10.1016/j.applthermaleng.2017.03.081

Copyright Elsevier

Additional Information 


\title{
Impact of the injector design on the combustion noise of gasoline partially premixed combustion in a 2 -stroke engine
}

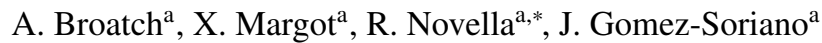 \\ ${ }^{a}$ CMT - Motores Térmicos, Universitat Politècnica de València, \\ Camino de Vera s/n, 46022 Valencia, Spain
}

\begin{abstract}
In this paper, a numerical Computational Fluid Dynamics (CFD) study is carried out with the purpose of understanding how the injector design may impact on the in-cylinder processes, which cause noise emission. This study is based on a combination of the gasoline partially premixed combustion concept with a new high speed direct injection 2-stroke engine, which emerges as a promising solution able to comply with nitrous oxides and particulate matter emissions standards, while ensuring combustion control and stability. The original engine configuration is varied by modifying the included spray angle and the number of injector nozzles in order to evaluate other design solutions for mitigating combustion noise. Results show that the maximum pressure time-derivative achieved during the combustion is the most influential parameter on the acoustic response of the in-cylinder noise source. However, they also evidence that for some operation conditions the resonance phenomena can enhance their contribution, thus playing a relevant role in the engine noise level. Further analysis allowed to identify three combustion-related parameters, which characterize this phenomenon and allow identifying key paths to minimize its levels.
\end{abstract}

Keywords: Gasoline PPC concept, 2-stroke engine, Combustion noise, Resonance, CFD Modelling

\section{Introduction}

In the last decade, adverse effects of the global warming have increased considerably, raising the concern about the environmental contamination and its consequences to life on Earth. In this context, at the Paris climate conference (COP21), 195 countries adopted a universal and legally-binding global climate deal [1]. Governments agreed on keeping the annual increase in global average temperature below $2^{\circ} \mathrm{C}$. Consequently, they should scale up their efforts and support actions to reduce emissions, especially in terms of carbon dioxide $\left(\mathrm{CO}_{2}\right)$. In addition, other exhaust emissions, such as nitrous oxides (NOx) or particulate matter (PM), are strictly controlled for their negative impact on human health [2].

The transport sector represents nearly $26 \%$ of the total $\mathrm{CO}_{2}$ emissions. In particular, the passenger cars segment is the largest source of both greenhouse and pollutant emissions in vehicles. Hence, the engine manufacturers have been forced to develop advanced systems to ensure fulfillment of the pollutant emissions standards, while improving engine performance, and therefore $\mathrm{CO}_{2}$ emissions. Nowadays the advanced systems technology present in the compression ignition (CI) diesel engines and spark ignition (SI) engines for automotive applications have become really complex and expensive. In both engine concepts NOx and PM emissions can be mitigated by a combination of close control of the combustion process with the newest exhaust after-treatment solutions. However, these passive solu-

${ }^{*}$ Corresponding author. Tel.: +34 9638796 50, fax: +34 963877659 , email: rinoro@mot.upv.es tions worsen fuel consumption and increase engine costs, compromising both compliance with $\mathrm{CO}_{2}$ emissions levels and customers' purchasing decision.

Advanced low temperature combustion (LTC) concepts arise as a solution to reduce after-treatment costs and fuel consumption. They have been thoroughly investigated for their advantage in reducing NOx and soot emissions simultaneously. In Diesel homogeneous charge compression ignition (HCCI) or premixed charge compression ignition (PCCI), fuel is ignited in highly premixed conditions to avoid soot formation, whereas NOx production is inhibited by decreasing the local temperatures with large amounts of exhaust gas recirculation (EGR) [3, 4]. The main issues with these concepts concern the over-mixed blend and the liquid fuel impingement on the cylinder/piston walls, which increase the unburned hydrocarbons (HC) and carbon monoxide (CO) emissions [5, 6]. Newest combustion concepts, such as gasoline partially premixed combustion (PPC) operate with partially premixed charges, between completely premixed and fully diffusive conditions. Investigations have confirmed the suitability of this combustion concept to achieve really low emissions of both NOx and soot particulates, while keeping the engine indicated efficiency. [7, 8].

The main drawback of the gasoline PPC concept resides in controlling the combustion phasing with the injection. Contrary to the conventional diesel combustion (CDC), the injection event alone does not ensure ignition, because the start of combustion mostly depends on the local thermodynamic conditions inside the chamber. This fact leads to a reduced load operation range between high-sharp combustions (knock) and unstable combustions (misfire). Nevertheless, there is evidence that 
a newly designed 2-stroke high speed direct injection (HSDI) CI engine [9] combined with multiple injection strategies [10] represents an option to extend the load range, by controlling the local charge conditions through the settings of the gas exchange process (GEP) $[11,12]$. Indeed, it is possible to keep the local equivalence ratios in a reactive band, thus avoiding the production of soot precursors while ensuring combustion efficiency and stability. However, the combustion process deteriorates because the ignition start is delayed, evincing a new trade-off between combustion efficiency and NOx-soot emissions $[13,14]$.

Despite the significant advances in the gasoline PPC concept, the increase in combustion noise compromises the compliance with future and even current legislations on noise levels. Moreover, the customers' sense of comfort is strongly influenced by how they perceive the engine noise. Therefore, current research efforts are focused on reducing the overall combustion noise levels $[15,16]$ and improving the sound quality of the engine noise $[17,18]$.

Combustion noise in $\mathrm{CI}$ engines results from the pressure and mechanical forces interaction during the combustion process. The sudden pressure rise caused by the premixed combustion phase reverberates directly on the combustion chamber walls and emits noise through the engine block vibration. Moreover, these pressure forces induce additional vibrations when they are transmitted by the moving elements in the cylinder $[19,20]$. Both forces depend strongly on the fuel-burning velocity, and hence on the rate of heat release (RoHR) [21, 22]. Additionally, there are high frequency pressure oscillations inside the cylinder, related to the unsteady process known as combustion chamber resonance [23], which also contribute to the engine noise. The interaction and reflection of the pressure waves generate gas oscillations that follow a series of patterns commonly named modes of resonance. Due to these modes the variations in the oscillation amplitudes in the combustion chamber are significant. The characteristic frequencies of these modes depend on the gas temperature and the combustion chamber geometry [24]. Hence, in a typical internal combustion engine (ICE), the frequencies associated with the axial (longitudinal) and transversal (radial and azimuthal) modes of third order or higher are out of the human hearing range. The maximum amplitude of these modes is linked to the achieved pressure gradients and the relative ignition locations inside the combustion chamber $[25,26]$. This complex phenomenon has a significant impact on the radiated engine noise because the characteristic excitation frequency span is in the highly sensitive human perception range $[16,17]$.

Broatch et al. [22] demonstrate that the main contribution to the overall noise radiated by the engine in gasoline PPC strategies comes from the maximum pressure time-derivative associated with the premixed combustion, and that the contribution of the resonance phenomenon is irrelevant for the overall noise. However, this research work does not consider all possible operation conditions, nor the sound quality. In fact, the contribution of the resonance cannot be dismissed when considering the whole operation range and it has to be taken into account for sound quality purposes [18].
Decreasing the maximum pressure time-derivative by controlling the fuel energy release seems to be the key point to reduce combustion noise in the gasoline PPC concept. Benajes et al. $[27,13]$ demonstrate that it is possible to accurately manage the combustion process by using multiple injection strategies. However, they also suggest a complete redesign of the combustion system (bowl and injector geometry) to increase the engine capabilities and to achieve further improvements in terms of emissions and efficiency levels.

In this framework, the main objective of this research is to analyze the impact of the injector design on the combustion noise source in a 2-stroke HSDI CI engine operated with the gasoline PPC concept. In order to attain this target, the effects of the injector design parameters on the RoHR trace and their contribution to the noise source should be understood. In the next three sections, a detailed description of the experimental set up and numerical tools is given. A validation of the numerical results is shown in Section 5. The results obtained are then presented in Section 6 and also discussed in Section 7. Finally, the conclusions obtained from this study are summarized in Section 8.

\section{Experimental setup}

\subsection{Engine architecture}

The experimental data needed for the validation of the CFD model was obtained from a single-cylinder research version of a new engine concept characterised by a 2-stroke HSDI CI engine with poppet valves scavenge loop. The main specifications of this engine are included in Tab. 1 and the injector system characteristics and fuel properties are displayed in Tab. 2.

The cylinder head and combustion chamber geometry shown in Fig. 1 have a particular design in order to optimize the scavenging of burnt gases. The characteristic scavenge loop of a 2-stroke engine with poppet valves, commonly known as hook scavenge, presents a serious disadvantage: the high short-circuit ratio. In order to reduce these losses, the intake ports have a tangential design with a masked surface, or staged roof geometry, for blocking the air flow between the intake and exhaust valves. This design guides the fresh charge along the cylinder wall and towards the squish region of the piston, thus avoiding the direct path between the intake and exhaust ports. This geometry allows achieving the best compromise between scavenging efficiency, acceptable permeability and complexity of the combustion chamber design [28].

The valves are actuated by a double-overhead camshaft and the timing control relies on a hydraulic cam-driven Variable Valve Timing (VVT) system. Due to its flexibility to set the overlap period between the intake and exhaust and to adapt the effective compression and expansion ratios, this system can modify the air management features in order to enlarge the operation range.

The engine is equipped with a common rail fuel injection system, which grants a maximum rail pressure of $110 \mathrm{MPa}$ using gasoline fuel. The injector configuration has 8 orifices with a $90 \mu \mathrm{m}$ nozzle diameter and an included angle of $148^{\circ}$. Mass 
Table 1: Engine specifications and injection system characterization

\begin{tabular}{|c|c|}
\hline Engine type & 2-stroke HSDI Compresion Ingition \\
\hline Number of cylinders [-] & 1 \\
\hline Displacement $\left[\mathrm{cm}^{3}\right]$ & 365 \\
\hline Bore - Stroke $[m]$ & $0.076-0.0805$ \\
\hline Connecting rod length $[\mathrm{m}]$ & 0.143 \\
\hline Compression ratio (geometric) & $17.8: 1$ \\
\hline Compression ratio (effective) & From $13.0: 1$ to $8.8: 1$ \\
\hline Number of valves [-] & 2 intake and 2 exhaust \\
\hline Type of scavenge & Poppet valves with scavenge loop \\
\hline Valvetrain & Double overhead camshaft with VVT \\
\hline Nominal intake valve timing [cad aTDC] & $\mathrm{IVO}=161.9-\mathrm{IVC}=251.6$ \\
\hline Nominal exhust valve timing [ $\mathrm{cad}$ aTDC] & $\mathrm{EVO}=122.6-\mathrm{EVC}=226.9$ \\
\hline Injection system [-] & Delphi DFI1.5 Common rail HSDI system \\
\hline Injector nozzle design $[0-$ holes $-\mu m]$ & $148-8-90$ \\
\hline Maximum allowed injection pressure $[\mathrm{MPa}]$ & 110 \\
\hline
\end{tabular}

Table 2: Fuel properties

\begin{tabular}{ll}
\hline Test fuel [-] & Unleaded gasoline with lubricity additive \\
Research octane number [-] & 94.6 \\
$\mathrm{H} / \mathrm{C}$ ratio $[\mathrm{mol} / \mathrm{mol}]$ & 1.76 \\
O/C ratio $[\mathrm{mol} / \mathrm{mol}]$ & 0 \\
Oxygen content $[\mathrm{m} / \mathrm{m}]$ & $<0.17 \%$ \\
Stoichiometric air $/$ fuel ratio (by mass) $[-]$ & 14.37 \\
LHV $[\mathrm{MJ} / \mathrm{kg}]$ & 42.820 \\
Density $\left(15^{\circ} \mathrm{C}\right)\left[\mathrm{kg} / \mathrm{m}^{3}\right]$ & 758.1 \\
Kinematic viscosity $\left(40^{\circ} \mathrm{C}\right)[\mathrm{cSt}]$ & 0.44 \\
\hline
\end{tabular}

flow rate and spray momentum flux were measured in dedicated test rigs [29] in order to provide the most realistic injection characterisation for the CFD simulations. The piston bowl geometry of conventional design provided a geometric compression ratio of 17.6 optimized for operating in CDC.

\subsection{Test cell characteristics}

The engine was assembled in a fully instrumented test cell equipped with all auxiliary devices required for engine operation. An external compressor supplied the intake air and simulated the boost conditions. The exhaust back-pressure produced by the turbine was generated and controlled by means of a throttle valve located downstream of the exhaust settling chamber. The installation also included independent water and oil cooling circuits, and an additional low EGR system to provide arbitrary levels of cooled exhaust gas even at very high intake boost pressures.

The in-cylinder pressure was measured with a Kistler 6061B pressure transducer placed between the intake and exhaust valves opposite the glow plug location, while a different piezoresistive pressure sensor was used to reference this pressure signal. Instantaneous high frequency signals, such as cylinder pressure were sampled using a dedicated acquisition system and recorded during 100 engine cycles for each operation condition. These signals were also registered with a sample frequency of $45 \mathrm{kHz}$, ensuring a free-aliasing bandwidth similar to the hu- man hearing domain $-20 \mathrm{~Hz}$ to $20 \mathrm{kHz}-$ according to Nyquist's criterion [30].

The most relevant combustion parameters, such as maximum pressure time-derivative, maximum cylinder pressure, rate of heat release and combustion phasing angles were calculated from the in-cylinder pressure by means of the energy equation and some simplifications [31, 32]. This equation was solved assuming uniform pressure and temperature throughout the whole combustion chamber volume and yielded the instantaneous mean temperature and the heat release. In this paper, the maximum pressure time-derivative was considered in angular units $(\mathrm{MPa} / \mathrm{cad})$ because the engine speed was constant and equal to $1500 \mathrm{rpm}$ in all considered tests.

\section{Numerical model setup}

The commercial CFD code CONVERGE was chosen to analyze the in-cylinder phenomena related to the noise generation and propagation. The three-dimensional model, shown in Fig. 1, was implemented by following the finite volume method in order to approximate the governing conservation equations. The computational domain, which included the complete cylinder geometry and intake-exhaust manifolds, was discretized using a structured mesh of hexahedrons with a base cell size of 3 $\mathrm{mm}$. This allows performing full cycle simulations, comprising GEP and both compression and combustion phases. The base 
mesh size was reduced by applying a grid scale factor or level of refinement in areas where the complexity of the physical and chemical phenomena increased. For instance, three levels of grid refinement were added close to the combustion chamber walls where the boundary layer is critical for the heat transfer. This parameter changes the base grid size according to

$$
l_{\text {scaled }}=\frac{l_{\text {base }}}{2^{n}}
$$

where $n$ is the level of refinement and, $l_{\text {base }}$ and $l_{\text {scaled }}$ are the base cell size and the new grid size, respectively.

In order to improve the accuracy for the simulation of the pressure waves reflection and interaction phenomena, three supplementary grid refinements were made in the whole cylinder during the combustion process. The latter grid properties were also considered in the spray zones to enhance the precision of the chemical reactions equations and spray properties modelling (atomisation, break-up, coalescence, etc.) In addition, an adaptive mesh refinement algorithm (AMR) was activated to increase the spatial resolution where both velocity and temperature gradients were significant. The total number of cells depended on the simulation timing and varied between $1.5 \times 10^{6}$ cells at the Bottom Dead Center (BDC) and $0.5 \times 10^{6}$ at Top Dead Center (TDC).

Although the combustion event can significantly change when the injector configuration is modified, the thermodynamic conditions after the GEP are not excessively altered. Thus, a previous simulation of the GEP, between exhaust valve opening (EVO) and intake valve closing (IVC), was performed in order to provide more realistic flow conditions for combustion calculations. Once this simulation was finished, the resulting flow conditions at IVC were considered as initial conditions for simulating the combustion phase or closed cycle.

In order to optimize the calculation time a dynamic time step strategy was used based on the Courant number, which allows estimating the time step based on the cell size and a characteristic velocity. Thus the time step for the compression and injection phases was calculated with a characteristic velocity equal to the flow velocity, whereas the speed of sound was considered during the combustion. As a result, the computational time was reduced without loss of accuracy of the in-cylinder acoustic field.

Boundary conditions have been set by means of OD models and also with direct measurements. Solid walls such as cylinder liner, intake-exhaust manifolds, piston and head were considered isothermal and they were estimated by the lumped model proposed by Torregrosa el al. [33]. The measured instantaneous pressure at the manifolds were used in the inflow/outflow boundaries; moreover the temperature in these is assumed constant and equal to the mean value registered during the experiments.

The simulated pressure was obtained at multiple monitor points, which were distributed uniformly in the combustion chamber. This method allows registering high frequency pressure oscillations and identifying the resonant modes. Additionally, a monitor placed at the same location as the pressure transducer
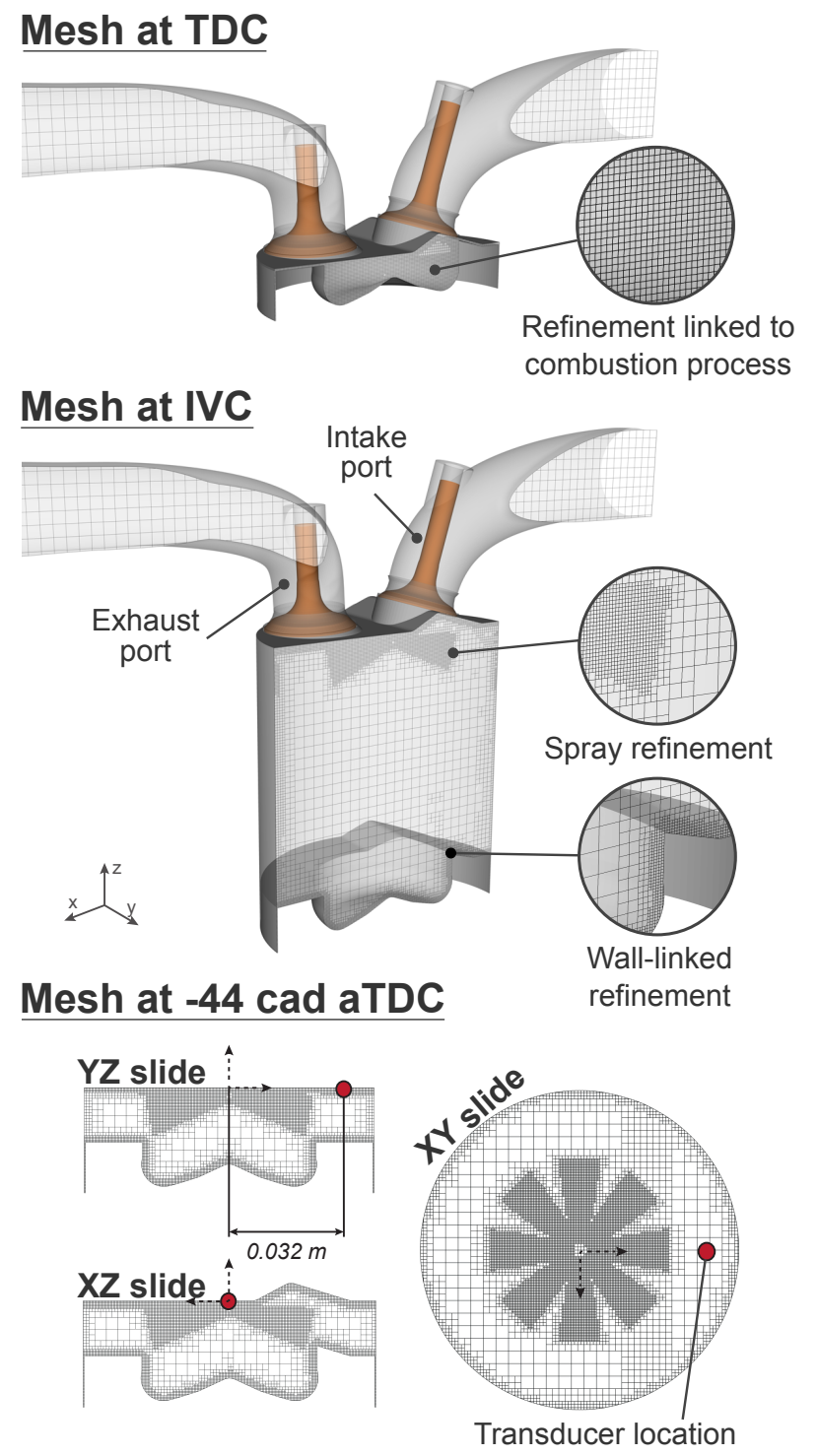

Figure 1: Computational domain and mesh characterization of the engine architecture at different calculation phases.

was used to take into account the resonance effects in the validation [25, 34]. Pressure traces were sampled at a frequency of $50 \mathrm{kHz}$ to ensure enough free-aliasing bandwidth to cover the human hearing range.

The Unsteady Reynolds Averaged Navier-Stokes (U-RANS) approach was used to approximate the turbulent flow properties. In particular, the renormalisation group (RNG) $k-\epsilon$ model [35] with estimated wall heat fluxes [36] was applied for this purpose. The injection event was simulated by the standard Discrete Droplet Model (DDM) [37] and the spray properties were modelled by the Kelvin-Helmholtz Rayleigh-Taylor (KH-RT) model [38]. The injection rate profile was obtained from the experimental data base available after the injector characterisation, based on mass flow rate and spray momentum flux measurements at similar thermodynamic conditions to those registered during the engine operation [39]. A chemical mechanism corresponding to a Primary Reference Fuel (PRF) blend of n- 
heptane and iso-octane was employed as surrogate fuel. The Diesel fuel ignition features were simulated by deactivating the iso-octane reactions. A reaction mechanism with 42 species and 168 reactions was considered for PRF oxidation [40].

The return time for a full cycle simulation was about $85 \mathrm{~h}$ when the calculation was divided into 32 parallel processors. In the same way, compression-combustion cycle simulations were performed in about $60 \mathrm{~h}$.

\section{Combustion noise characterisation}

Three common acoustic parameters were selected for characterising the combustion noise: the cylinder pressure level (CPL), the overall level $(\mathrm{ON})$ and the sound quality of the engine noise. The CPL is used to assess the source of the combustion noise and it is calculated by

$$
\mathrm{CPL}(\mathrm{dB})=10 \cdot \log \frac{P_{N}^{2}}{p_{0}^{2}}
$$

where $p_{0}$ is a reference sound pressure of $20 \mu \mathrm{Pa}$, which corresponds to the minimum human hearing threshold. In addition, $P_{N}$ is defined as

$$
P_{N}=\frac{1}{N} \cdot \sum_{f=f_{1}}^{f_{N}} P(f)
$$

where $\mathrm{N}$ is the number of harmonics between $f_{1}$ and $f_{N}$, and $P(f)$ represents the Fast Fourier Transform (FFT) of the incylinder pressure signal [21].

The overall level of engine noise, from now on termed ON, assesses the radiated noise by the engine structure. This acoustic response is highly non-linear and unsteady, and it is extremely affected by the engine block design [41, 42, 43]. A classical approach is traditionally used to link the in-cylinder pressure level with the radiated engine noise [44]. This estimation is based on assuming linear behaviour between the noise source and free-field conditions. Even though this simplification does not allow for an accurate prediction of the radiated noise level, it is useful for qualitative analysis, and several combustion noise metrics are defined taking into account this method. The authors applied this classical approach because the engine is a single-cylinder version for research purposes and the structure is not representative of a commercial engine design. The overall noise can be determined by applying Equation (2) to the spectrum of the engine noise. This spectrum is estimated by subtracting the block attenuation curve [45] from the in-cylinder pressure spectrum.

The subjectively perceived sound quality of the engine noise is also of paramount importance due to its impact on the customer acoustic perception. Khan et al. [46] have adopted multiple linear regression analysis in order to predict the relationship between the subjective judgement and the source of the combustion noise. Other authors [21] proposed an in-cylinder pressure decomposition, which allows identifying three frequency bands in the pressure spectrum. These bands are linked to one of the three ICE cycle parts: compression-expansion, combustion and resonance phenomenon. This method determined which parameters are the most influential in each frequency band. Payri et al. [17] verified that the maximum pressure time-derivative $\left((d p / d \alpha)_{\max }\right)$ and the energy of the resonance phenomenon $\left(\mathrm{E}_{\mathrm{res}}\right)$ correlate with the perceived sound quality of the Diesel combustion noise. In line with this publication, Broatch et al. [22] also demonstrated the relation between both combustion parameters and the in-cylinder pressure spectrum. While the $(d p / d \alpha)_{\max }$ affects the CPL generated in the medium band of frequencies, the high frequency band is characterised by the $\mathrm{E}_{\mathrm{res}}$. In this research, both combustion parameters were used to make a qualitative estimation of the perceived sound quality.

As is usually considered in the field of signal processing, $E_{\text {res }}$ is the signal energy of the resonant pressure oscillations

$$
\mathrm{E}_{\mathrm{res}}=\int_{I V C}^{E V O} p(t)_{r e s}^{2} d t
$$

where $p(t)_{r e s}$ is the pressure signal due to the resonance phenomenon and IVC and EVO are the limits of the time integral [25]. Simpler metrics such as peak pressure rise rate (PPRR) or ringing intensity (RI) are widely used in the literature for quantifying the global amplitude of the pressure oscillations. However, Shahlari et al. [47] have evidenced their weakness for characterising the resonance phenomenon when the combustion strategy, engine platform or operation conditions change. Thus, $\mathrm{E}_{\mathrm{res}}$ offers better reliability to quantify the resonance phenomenon because it is based on the pressure trace and not on indirect parameters [48].

Due to its connection with the amplitudes of the resonant modes, this parameter is useful to display the patterns of the modes in the combustion chamber. However, because of these effects, it is not suitable for comparing the level of resonance between different operation points. Hence a global parameter, which represents the global energy of the resonance phenomenon, is proposed to overcome this limitation

$$
\mathrm{E}_{\mathrm{res}}^{\mathrm{total}}=\sum_{i=1}^{M} \mathrm{E}_{\mathrm{res}}^{i}
$$

where $\mathrm{M}$ is the number of monitors in the combustion chamber and $\mathrm{E}_{\mathrm{res}}^{i}$ is the energy of the resonance at the $i$ monitor [22].

\section{Validation}

An operation condition defined by a medium speed (1500 rpm) and medium-high load (1.04 MPa IMEP) was selected as baseline to validate the CFD model. Two additional tests were included in order to evaluate the model capability for reproducing experimental trends in terms of acoustic parameters. In both experiments, the second injection timing - defined by the Start of Energizing of the injector (SoE) - was varied while the operation conditions were kept similar to the baseline test. The main engine settings of these tests are presented in Tab. 3 .

The simulation of the complex phenomena linked to the combustion process, which contribute to the sound generation demands a thorough validation procedure to ensure that the 
Table 3: Main engine settings for all operation points evaluated in the validation procedure.

\begin{tabular}{|c|c|c|c|c|c|c|c|c|c|c|c|c|}
\hline $\begin{array}{l}\text { Test } \\
{[-]}\end{array}$ & $\begin{array}{l}\text { EGR } \\
{[\%]}\end{array}$ & $\begin{array}{l}p_{\text {int }} \\
{[\mathrm{MPa}]}\end{array}$ & $\begin{array}{l}\text { Overlap } \\
{[\mathrm{cad}]}\end{array}$ & $\begin{array}{l}\text { VVT (int, exh) } \\
{[\mathrm{cad}]}\end{array}$ & $\begin{array}{l}\text { Effective CR } \\
{[-]}\end{array}$ & $\begin{array}{l}p_{\text {rail }} \\
{[\mathrm{MPa}]}\end{array}$ & $\begin{array}{l}\text { SoE1 } \\
{[\text { cad aTDC] }}\end{array}$ & $\begin{array}{l}\text { SoE2 } \\
{[\text { cad aTDC] }}\end{array}$ & $\begin{array}{l}\text { SoE3 } \\
{[\text { cad aTDC }]}\end{array}$ & $\begin{array}{l}\text { Injected fuel } \\
{[\mathrm{mg} / \mathrm{str}]}\end{array}$ & $\begin{array}{l}\text { Fuel ratio } \\
{[-]}\end{array}$ & $\begin{array}{l}\text { Air/Fuel ratio } \\
{[-]}\end{array}$ \\
\hline $01\left(\mathrm{SoE} 2-40^{\circ}\right)^{*}$ & 43.53 & 0.275 & 78.4 & $(5,20)$ & 12.15 & 85 & -60.00 & -40.00 & -2.00 & 19.10 & $20 / 64 / 16$ & 21.96 \\
\hline $02\left(\mathrm{SoE} 2-42^{\circ}\right)$ & 43.66 & & & & & & & -42.00 & & & & 22.12 \\
\hline $03\left(\mathrm{SoE} 2-34^{\circ}\right)$ & 43.56 & & & & & & & -34.00 & & & & 22.42 \\
\hline
\end{tabular}

*Baseline test.

numerical model results are representative of the combustion noise source. This method is based on the methodology proposed by Broatch et al. [22] who compare the in-cylinder pressure in both time and frequency domains. Usual validation procedures use the in-cylinder pressure trace averaged over a given number of recorded cycles, but this procedure modifies the pressure spectrum in the high frequency range. Here instead, the most representative cycle among those measured is selected by means of a statistical study in order to keep the pressure components in the high frequencies [25, 26, 22]. In addition, the position of the pressure transducer also has a strong influence on these frequencies. Hence the simulated in-cylinder pressure is registered with a monitor located at the same point as the transducer. The RoHR profiles are compared in order to check the combustion evolution.

The experimental and the simulated in-cylinder pressure traces are compared in Fig. 2a. The CFD model correctly predicts the in-cylinder pressure. Indeed, the pressure prediction shows a similar deviation as measurements dispersion (see Fig. 2). The RoHR profiles show that the combustion phasing is slightly delayed and its peak value is over-estimated. However, these differences do not affect the maximum peak pressure in a significant way. This effect may be attributed to a minor underestimation of the effective compression ratio, given that the estimation of this parameter highly depends on material deformations and blow-by losses that the model does not take into account. For the pressure spectrum, presented in Fig. 2b, the model is also able to reproduce the experimental trends in the whole range of considered frequencies. The characteristic frequency and the amplitude of the two first transversal modes are accurately estimated. Additionally, four commonly used acoustic parameters, all of them detailed in Section 4, were used to analyse the impact of these results on the external acoustic field. These parameters were compared not only for the reference operation point, but also for two extra tests with the same operation conditions and different injection strategies (see Tab. 3), in order to perform a more rigorous validation procedure. Figures $2 \mathrm{c}$ to $2 \mathrm{f}$ show respectively a comparison of the cylinder pressure level, the overall noise level, the maximum pressure time-derivative $\left((d p / d \alpha)_{\max }\right)$ and the resonance energy at the transducer location $\left(\mathrm{E}_{\text {res }}^{\text {trans }}\right)$ for the three analysed cases. The trends are well reproduced by the model but some differences can be seen in test $02\left(\operatorname{SoE} 2-42^{\circ}\right)$. This is attributed to the over-estimation of the $(d p / d \alpha)_{\max }$ (see Fig. 2e) and its indirect effect on the rest of the parameters. However, taking into account that the model was not adjusted for the two extra operation points, the validation results are reasonably consistent with the trends followed by the measurements. Hence, it is possible to claim that the model has enough capability to reproduce and characterize the combustion noise source.

\section{Results}

This research work has been performed in the frame of the gasoline PPC concept optimisation for a 2-stroke engine. Broatch et al. [22] showed how the achieved combustion noise levels compromise the applicability of this combustion concept. They also evidenced that the combustion noise can be controlled by closely managing the RoHR due to the combustion process. In this paper, the authors redesigned the combustion system by modifying the injector geometric characteristics in order to increase the system capabilities. This work was made by using the CFD model described in Section 3 with test $01\left(\operatorname{SoE} 2-40^{\circ}\right)$ operation settings (see Tab. 3). Two aspects were analysed according to the injector modifications: in the first one the included spray angle (IA) was varied to guide the fuel to the centre of the bowl, and in the second one the number of injector nozzles (NN) was modified, while the total injection area was kept constant. In both studies the injection rate remained fixed. Moreover, the nozzles diameter of the injector holes in the NN study was adapted to maintain the overall injection area, assuming that the discharge coefficient remains constant for every hole. Therefore, the nozzle diameter decreases as the number of nozzles increase. A detailed information about these parameters is included in Tab. 4.

Figure 3 shows the results of the two studies in terms of incylinder pressure and RoHR. Examination of the results for the IA study (Fig. 3a) shows that the time delay is reduced for included spray angles below 148 degrees. With these values of IA the spray is fully directed towards the interior of the piston bowl where the local temperatures are higher and the spray mixing is more efficient. Since the mixing rate is increased, the ignition delay is too small to achieve lean mixtures, causing high reaction blends at the start of combustion. The combustion tends to become sharper and shows a maximum value for the RoHR approximately constant.

For the NN study, the ignition delay is reduced as the number of nozzle holes increases. Mixing conditions and local temperatures reduce the ignition delay by achieving more reactive blends. However, the duration of the combustion remains nearly constant while the maximum RoHR is increased. In addition, in comparison to the IA study, the combustion process is less abrupt with longer RoHR profiles.

Four typical acoustic parameters, described in section 4 and presented in Fig. 4 have been used to characterise the combustion noise behaviour in both studies. Several effects can be observed in the in-cylinder acoustic field due to the combustion behaviour described above. The CPL shows an increasing trend 
Table 4: Injector configuration for all simulations analysed in this investigation.

\begin{tabular}{|c|c|c|c|}
\hline Test & IA $[d e g]$ & NN [-] & Nozzle diameter $[\mu m]$ \\
\hline 01 (IA148º-NN8)* & 148 & 8 & 90 \\
\hline 04 (IA90-NN8) & 90 & 8 & 90 \\
\hline 05 (IA110-NN8) & 110 & 8 & 90 \\
\hline 06 (IA135ㅇNㅇ) & 135 & 8 & 90 \\
\hline 07 (IA148ㅇNㄴ) & 148 & 12 & 60 \\
\hline 08 (IA148º-NN10) & 148 & 10 & 72 \\
\hline
\end{tabular}

*Baseline test
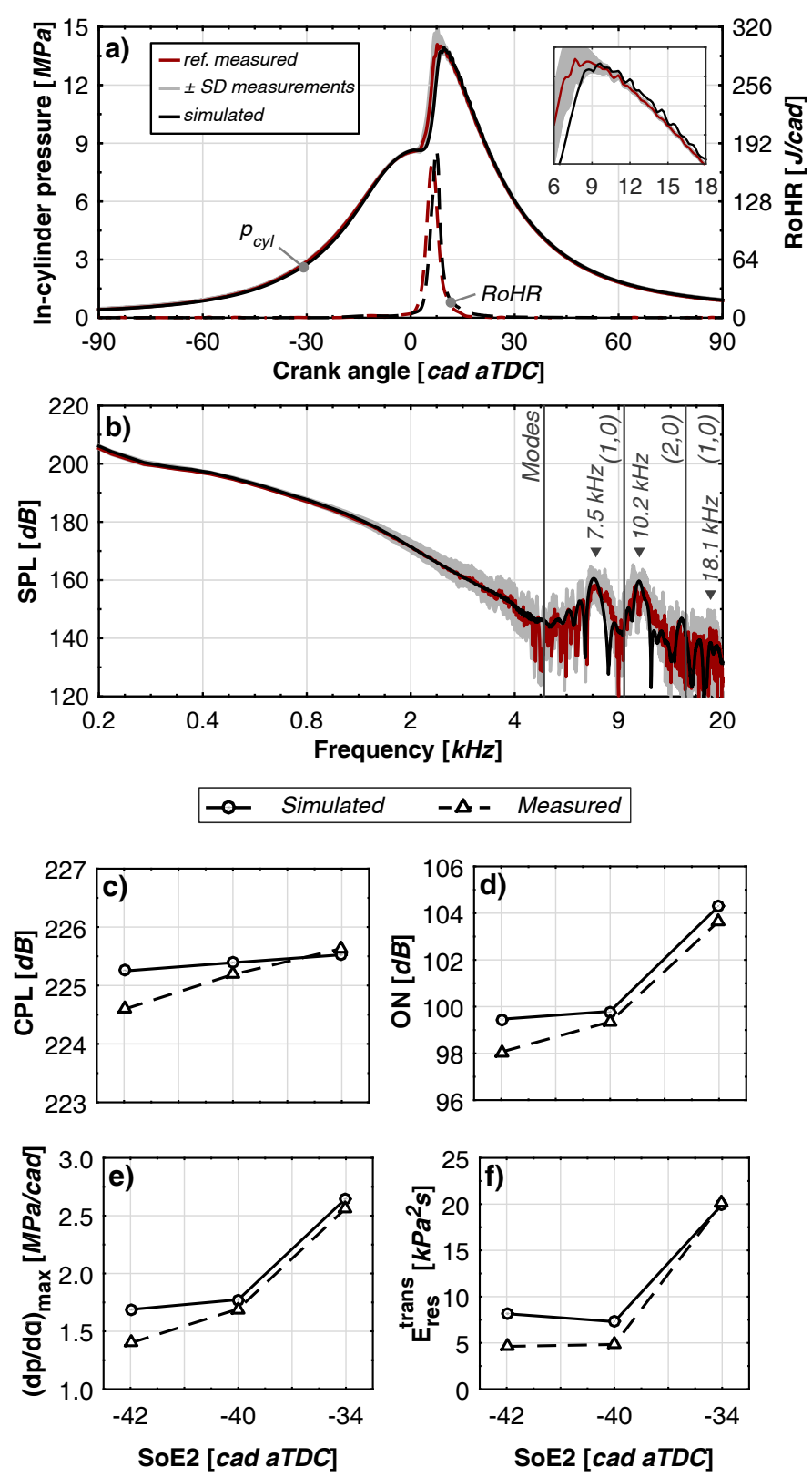

Figure 2: Comparison between measured and CFD calculated, measurements dispersion is represented by their standard deviation (SD). a) In-cylinder pressure and RoHR traces, b) Pressure spectra traces, c) to f) CPL, ON, $(d p / d \alpha)_{\max }$ and $\mathrm{E}_{\mathrm{res}}^{\mathrm{trans}}$ parameters trends.
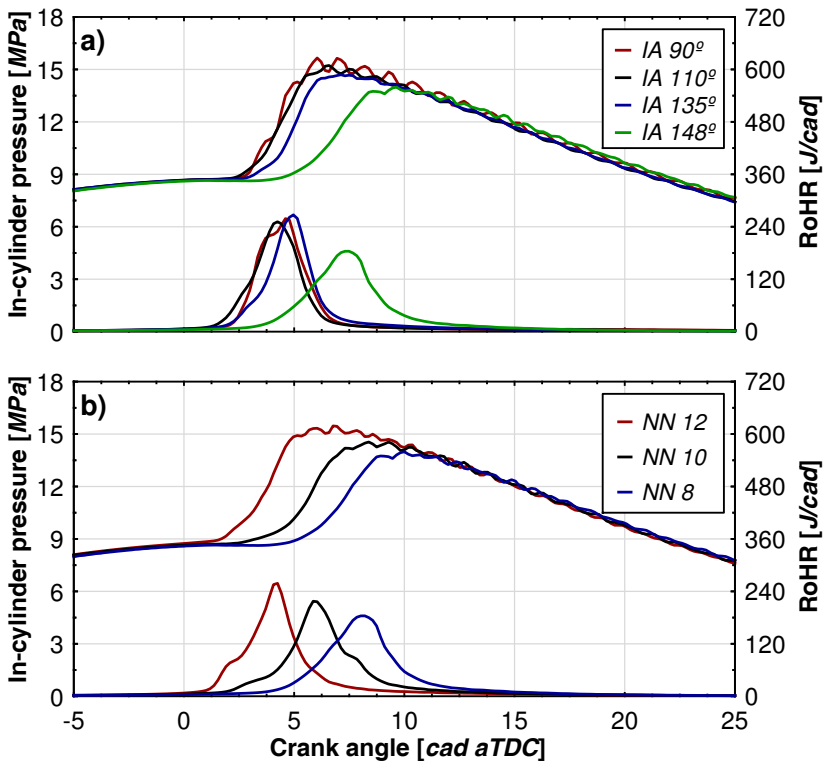

Figure 3: Comparison of the in-cylinder pressure and RoHR traces. a) Included spray angle study, b) Number of injector nozzles study.

as the included angle is reduced and the number of nozzles is increased. The ON levels are significantly incremented if the IA is reduced below 148 degrees, achieving a steady value around $104 \mathrm{~dB}$. In addition, this parameter rises as NN increases but, in this case reaches lower values. If these values are compared with Fig. 4c, it is evident that the ON levels follow the same trends as exhibited by the $(d p / d \alpha)_{\max }$ parameter. This confirms the conclusions obtained by Broatch et al. [22] who claim that the main contribution to combustion noise radiation in gasoline PPC concept comes from $(d p / d \alpha)_{\max }$ associated to the premixed combustion. However, the similar $(d p / d \alpha)_{\max }$ obtained in tests $04\left(\mathrm{IA} 90^{\circ}-\mathrm{NN} 8\right)$ and 07 (IA148 $\left.{ }^{\circ}-\mathrm{NN} 12\right)$ can produce different levels of overall noise. Indeed, tests 04 (IA90 ${ }^{\circ}-\mathrm{NN} 8$ ) and 07 (IA148 ${ }^{\circ}$ NN12) present very close values of the maximum pressure time-derivativel, while the $\mathrm{ON}$ is almost $1.5 \mathrm{~dB}$ lower in test 07 (IA148 - NN12). Th analysis of Fig. 4d reveals that the global energy of resonance is clearly higher in these two tests. Additionally, the gap between both tests is significant $(\simeq 32 \%)$ and it explains the difference in the overall noise levels. Thus, the resonance phenomenon can become an important aspect in some operation conditions, in which its high 

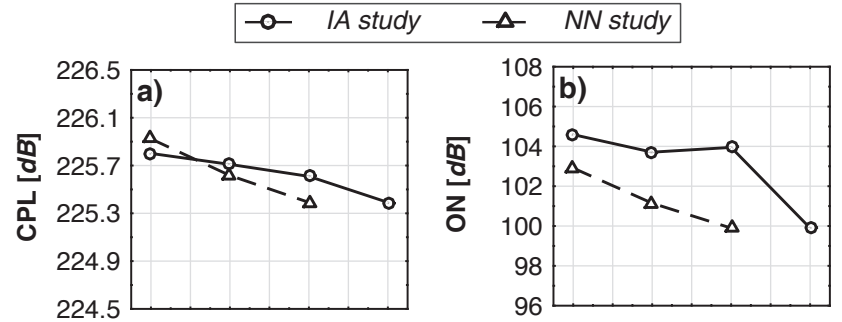

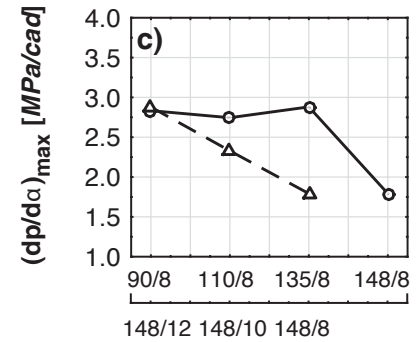

IA [] / NN [-]

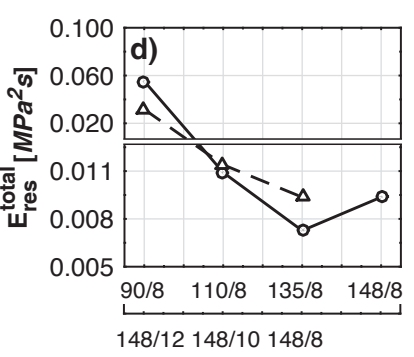

IA [] / NN [-]
Figure 4: Effects of the included spray angle and number of injector nozzles. a) Cylinder pressure level, b) Overall noise, c) Maximum pressure time-derivative, d) Energy of resonance.

energy values affect the overall noise and also the sound quality.

\section{Discussion}

The results presented here demonstrate that the combustion noise in gasoline PPC is mainly linked to the maximum pressure time-derivative but, in some conditions, the resonance phenomenon can contribute in a relevant way. Detailed analysis of the combustion process is reported in order to provide a better understanding of the resonance phenomenon in ICE combustion chambers.

Intuitively, the tendency is to think that the resonance phenomenon directly depends on the acoustic excitation intensity. In ICE this excitation is linked to the combustion process, with $(d p / d \alpha)_{\max }$ considered as the main characterisation parameter due to its direct relation with the fuel energy release. However, it is theoretically possible to demonstrate $[25,23]$ that some additional parameters can determine the standing waves behaviour, modifying both the amplitude and the characteristic frequency of resonant modes. In fact, in the previous section it has been shown how similar excitation levels obtained with different testing conditions cause large differences in the energy of resonance. In particular, tests 04 (IA90 ${ }^{\circ}$-NN8) and 07 (IA148 $-\mathrm{NN} 12$ ) exhibit very high levels of resonance energy in comparison with tests 05 (IA $110^{\circ}$-NN8) and 06 (IA135 ${ }^{\circ}$-NN8).

For this study, the RoHR was numerically integrated along the whole CFD domain with respect to the equivalence ratio $(\phi)$ and to the cylindrical coordinate $\left(R^{n o r m}\right)$ in order to analyse both temporal and spatial characteristics of the combustion process. The solutions are presented in Figs. 5a and 5b in which the horizontal axis represents the temporal evolution of the engine cycle, the vertical axis shows the integration variable ( $\phi$ or $R^{\text {norm }}$ ) and the colour scale displays the RoHR.
The sequence of pictures in Fig. 5a describes the combustion process in terms of fuel stratification. In tests $04\left(\right.$ IA $90^{\circ}$ NN8) and 07 (IA148 ${ }^{\circ}$ NN12) the combustion starts in nearstoichiometric mixtures $(\phi \simeq 1)$, causing high burning rates in this combustion phase. In addition, fuel in near-stoichiometric conditions is completely consumed before the leaner blends $(0.4<\phi<0.7)$ achieve their ignition limits. Consequently, a second ignition of these lean mixtures generates an additional acoustic excitation, which increases the resonance level inside the combustion chamber. This effect is similar to that observed in CDC with multiple injection strategies [16]. By contrast, tests 05 (IA $110^{\circ}$-NN8) and 06 (IA $135^{\circ}$-NN8) only show a single ignition located in the medium range of the equivalence ratio $(0.4<\phi<0.8)$, with the resonance below limited values. Therefore, the large difference in the resonance energy between tests 04-07 and 05-06 is related with the number of sequential ignitions.

However, this conclusion does not explain the differences in $\mathrm{E}_{\text {res }}$ levels between tests 05 and 06 , and also between 04 and 07. Comparing tests 05 (IA $110^{\circ}$-NN8) and 06 (IA135 ${ }^{\circ}$-NN8), both show a single ignition, but test 05 (IA110 - -NN8) presents a higher level of resonance with a somewhat lower $(d p / d \alpha)_{\max }$. Additionally, tests 04 (IA90 ${ }^{\circ}$-NN8) and 07 (IA148 - NN12) display different levels of $\mathrm{E}_{\mathrm{res}}$ with similar $(d p / d \alpha)_{\max }$ and the same number of sequential excitations. Torregrosa et al. [25] and Broatch et al. [26] demonstrated that the amplitude of the resonant modes is amplified as the maximum of the RoHR increases. Moreover, they state that the relative location of the ignition zones with respect to the nodes - or zero amplitude regions - can influence the frequency content of the spectrum between two consecutive resonant modes, and change the energy of resonance in a significant way. In addition, subsequent publications [22] have evidenced that the contribution of the first resonant mode is the most relevant in the total energy of resonance. So, an analysis of the radial position of the ignition areas could contribute to understand the resonance phenomenon.

Figure $5 \mathrm{~b}$ displays the results of an analogous procedure presented in Fig. 5a but, in this case the cylindrical coordinate $R^{\text {norm }}$ was selected as integration variable. $R^{\text {norm }}$ is the radial position normalized by the radius of the cylinder; it is zero at the centre of the bowl and one at the cylinder walls. These contour plots allow identifying where the energy release is located during the engine cycle. It is necessary to establish a criterion to determine the start of combustion and thus obtain the position of the ignition area. The start of pressure excitation (SoeP) was considered for this criterion, which is defined as the instant when the pressure wave due to the ignition event starts to develop. This moment practically coincides with the crank angle for $10 \%$ of fuel burnt (CA10). Figure 5c shows the distribution of the RoHR along the $R^{\text {norm }}$ coordinate at SoeP and the red line represents the average position of the energy release.

Table 5 shows remarkable differences in the radial location of the ignition between tests 05 (IA $110^{\circ}$-NN8) and 06 (IA $135^{\circ}$ NN8). The local thermodynamic conditions cause a smooth combustion close to the bowl limits in test 05 (IA110 -NN8), whereas in test 06 (IA $135^{\circ}-\mathrm{NN} 8$ ) the combustion law is sharper (as shown in Fig. 3a) and located at the centre of the bowl. 
Thus, the energy of resonance can be mitigated by forcing the ignition to start in the middle of the cylinder near the node of the first resonant mode.

Focusing on tests 04 (IA90 ${ }^{\circ}$-NN8) and 07 (IA148 ${ }^{\circ}$-NN12), it is necessary to analyse both sequential combustions separately, obtaining the excitation intensity $\left((d p / d \alpha)_{\max }\right)$ and position $\left(R^{\text {norm }}\right)$ of each one. Table 5 shows these parameters for both tests 04 (IA90 ${ }^{\circ}$-NN8) and 07 (IA148 ${ }^{\circ}$-NN12) and for each ignition. Both present slight differences in the radial location, but these differences do not explain the gap observed in the $E_{\text {res }}$ levels. A substantial difference is observed between the $(d p / d \alpha)_{\max }$ of the first ignition; while test 04 (IA90 ${ }^{\circ}$-NN8) exhibits $2.45 \mathrm{MPa} / \mathrm{cad}$, test 07 (IA148 ${ }^{\circ}$-NN12) only achieves a value of $1.54 \mathrm{MPa} / \mathrm{cad}$. Therefore, the gap in the resonance energy is explained not only by the position of the ignitions, but also by the intensity of all of them.

Although $\mathrm{E}_{\mathrm{res}}$ was widely used in the literature for its correlation with engine noise, it does not provide a detailed information about the pressure spectrum in the high frequency range. Indeed, it does not report about the frequency distribution of the resonant modes and their spatial patterns. Therefore, the contribution of this parameter to the understanding of the in-cylinder acoustic field is very limited.

For this reason, Fig. 6 shows a pressure spectrum comparison between tests 05-06 and tests 04-07 that provides more insight and overcomes this drawback. It gives an idea, at least in a qualitative way, about which are the most excited modes (mean spectrum) and also about their spatial variation $( \pm \mathrm{SD})$.

As reported above, test 05 displays a higher value of $E_{r e s}$ than test 06. According to the data presented in Fig. 6a, significant changes in the high frequency distribution are clearly visible. While the amplitude of the first mode is reduced, it is increased in higher order modes when the conditions change from test 05 to test 06 . In addition, the spatial dispersion seems to be correlated with the relevance of each mode. On the other hand, Fig. 6b. shows that the differences in the pressure spectra of tests 04 and 07 are smaller. Both tests follow the same trend in terms of the relevance of the modes, whereas their amplitudes are scaled.

Further analysis of the results shows that the trend in the high frequency spectrum is similar in tests 04,05 and 07 for which the position of the ignition is almost the same (see Tab. 5). Only in test 06 for which the ignition location is notably different, this trend changes and the second mode becomes the most dominant. Therefore, the ignition location has an impact not only on the global amplitude of the high frequency pressure spectra $\left(\mathrm{E}_{\text {res }}\right)$, but also on the relevance of the excited modes.

\section{Conclusions}

The impact of the injector design on the combustion noise of an engine operating with the gasoline PPC concept has been analyzed in this paper using CFD modelling. The model was validated by comparison with experiments, displaying consistent results in both temporal and frequency domains. In addition, the validation methodology was applied to various running
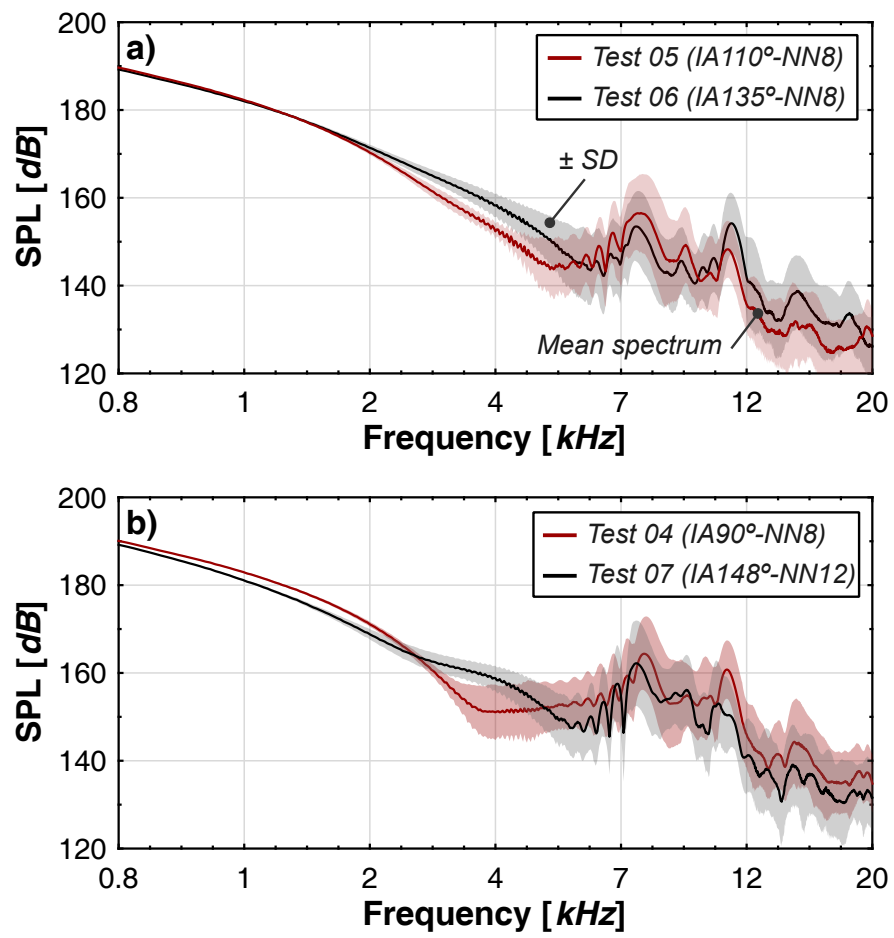

Figure 6: Comparison of the in-cylinder pressure spectra trends. The pressure spectrum averaged over all monitors distributed in the domain is plotted with its standard deviation (SD). a) Test 05 and 06, b) Test 04 and 07

conditions with the same operation settings but with different injection strategies to verify that the model reproduces the experimental trends correctly. Results evidenced the capability of the model to characterize the combustion noise source accurately.

The different injector configurations produce diverse fuel stratification conditions at the start of combustion, achieving higher reactive mixtures as the included angle decreases and the number of injector nozzles increases. This evidences that both the mixing conditions and local thermodynamic conditions are crucial in the combustion and its effects.

Results show how the combustion noise in the gasoline PPC concept is strongly linked to the intensity of the acoustic excitation $\left((d p / d \alpha)_{\max }\right)$. However, under certain operation conditions the resonance phenomenon can also play an important role. Indeed, with different stratification strategies it is possible to diminish the combustion noise by reducing the resonance level. This phenomenon is very sensitive to three parameters related to the combustion process: the intensity of the acoustic excitation $\left((d p / d \alpha)_{\max }\right)$, the number of sequential excitations and the relative location of the ignition $\left(R^{n o r m}\right)$. The quantity of fuel in near-stoichiometric conditions mainly determines the acoustic excitation intensity, due to the high reacting rates linked to the stoichiometric mixtures. If the combustion process is divided in multiple ignition phases, the resonance level increases significantly, and becomes the most influential parameter in the amplitude of the resonance oscillations. In addition, the relative position of the ignition also contributes significantly to the resonance level and influences the modes distribution of the high 
a)

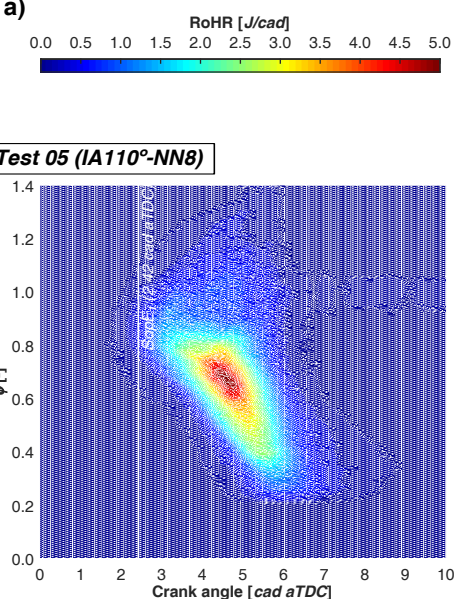

Test 06 (IA135 -NN8)
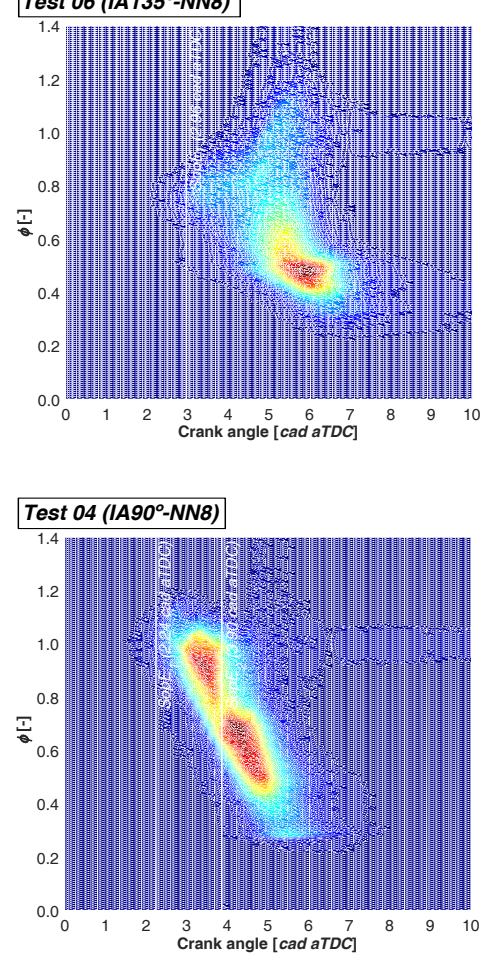

Test 07 (IA148 ${ }^{\circ}$-NN12)

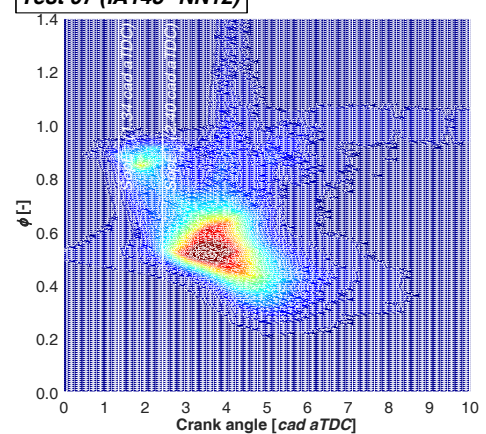

b)
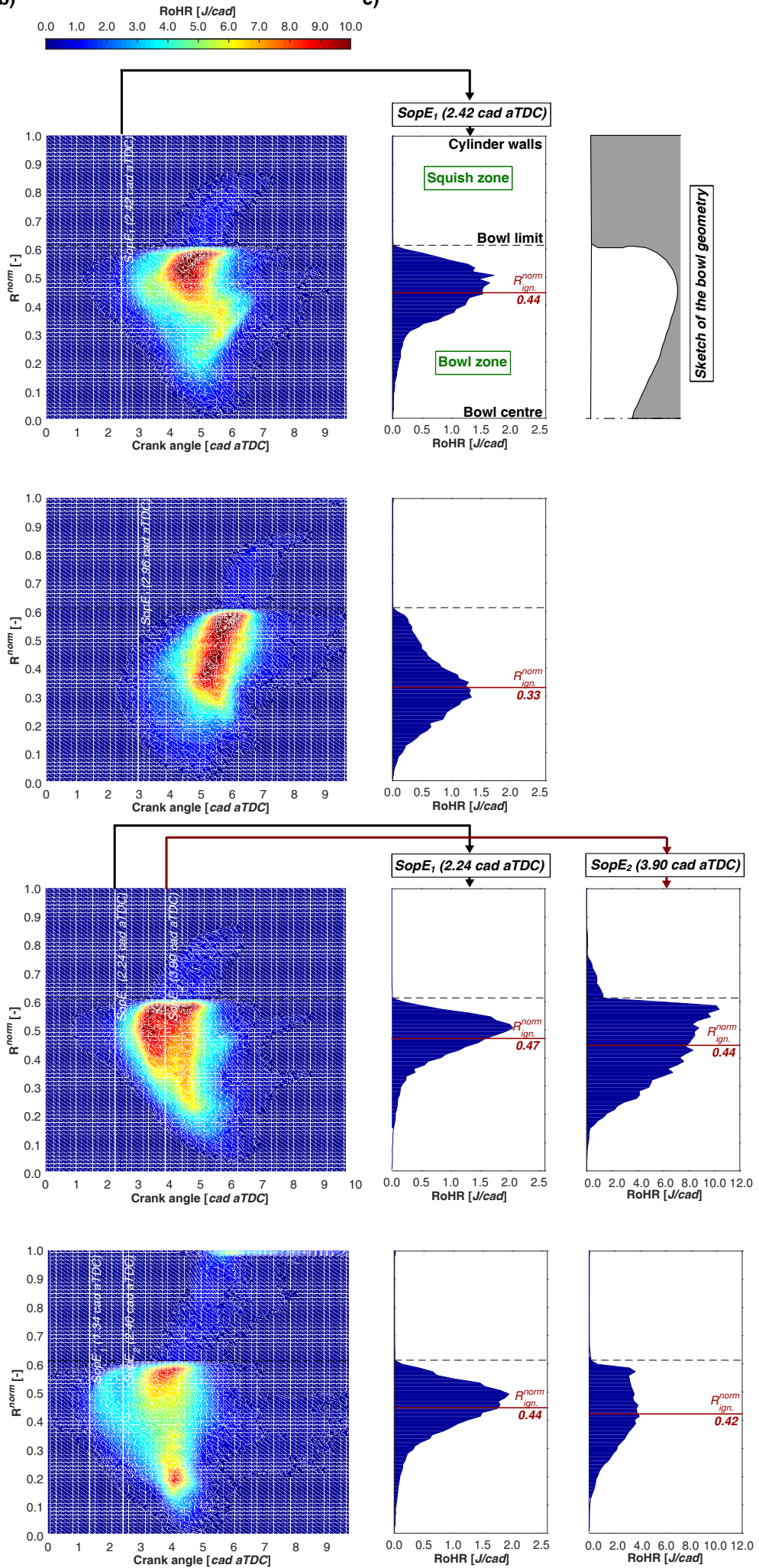

Figure 5: Results of the combustion process analysis for tests 05, 06, 04 and 07. a) RoHR contours along equivalence ratio and crank angle degree, b) RoHR contours along the radial dimension of the cylinder engine, c) Histogram of RoHR along the radial dimension of the cylinder engine at the start of combustion (SoeP). 
Table 5: Combustion characterisation parameters $\left(\operatorname{SoeP},(d p / d \alpha)_{\max }\right.$ and $\left.R^{\text {norm }}\right)$ in tests 04, 05, 06 and 07

\begin{tabular}{|c|c|c|c|c|c|c|}
\hline \multirow[b]{2}{*}{ Test } & \multicolumn{3}{|c|}{ First ignition } & \multicolumn{3}{|c|}{ Second ignition } \\
\hline & $\begin{array}{c}\operatorname{SoeP}_{1} \\
{[\mathrm{cad} \text { aTDC }]}\end{array}$ & $\begin{array}{c}(d p / d \alpha)_{\max } \\
{[\mathrm{MPa} / \mathrm{cad}]}\end{array}$ & $\begin{array}{c}R_{1}^{\text {norm }} \\
{[-]}\end{array}$ & $\begin{array}{c}\mathrm{SoeP}_{2} \\
{[\mathrm{cad} \text { aTDC }]}\end{array}$ & $\begin{array}{c}(d p / d \alpha)_{\max _{2}} \\
{[\mathrm{MPa} / \mathrm{cad}]}\end{array}$ & $\begin{array}{c}R_{2}^{\text {norm }} \\
{[-]}\end{array}$ \\
\hline $05\left(\mathrm{IA} 110^{\circ}-\mathrm{NN} 8\right)$ & 2.42 & 2.75 & 0.44 & - & - & - \\
\hline 06 (IA135 $-\mathrm{NN} 8)$ & 2.96 & 2.88 & 0.33 & - & - & - \\
\hline 04 (IA900-NN8) & 2.24 & 2.45 & 0.47 & 3.90 & 2.83 & 0.44 \\
\hline 07 (IA148 ${ }^{\circ}$-NN12) & 1.34 & 1.54 & 0.44 & 2.40 & 2.88 & 0.42 \\
\hline
\end{tabular}

frequency pressure spectrum.

However, improvements in terms of resonance levels require an accurate control of the combustion process in order to determine the $(d p / d \alpha)_{\max }$, the number of sequential ignitions and their position. This control cannot be achieved with conventional injector designs; it is necessary to explore different configurations with optimized injector/bowl designs or controlled ignition location systems.

\section{Acknowledgements}

The equipment used in this work has been partially supported by FEDER project funds "Dotación de infraestructuras científico técnicas para el Centro Integral de Mejora Energética y Medioambiental de Sistemas de Transporte (CiMeT), (FEDERICTS-2012-06)" from the operational program of unique scientific and technical infrastructure of the Spanish Ministerio de Economía y Competitividad. J. Gomez-Soriano is partially supported by an FPI contract (FPI-S2-2016-1353) of the "Programa de Apoyo para la Investigación y Desarrollo (PAID-0116)" of the Universitat Politècnica de València.

The authors want to express their gratitude to CONVERGENT SCIENCE Inc. and IGNITE3D Engineering GmbH for their kind support for the CFD calculations with the CONVERGE software.

\section{References}

[1] CDP Global Climate Change Report 2015, Tech. rep., Carbon Disclosure Project (October 2015).

[2] M. Kampa, E. Castanas, Human health effects of air pollution, Environmental Pollution 151 (2) (2008) 362 - 367, proceedings of the 4th International Workshop on Biomonitoring of Atmospheric Pollution (With Emphasis on Trace Elements). doi:http://dx.doi.org/10.1016/ j.envpol.2007.06.012.

[3] H. Ryo, Y. Hiromichi, HCCI combustion in a DI Diesel engine, in: SAE Technical Paper, Vol. 2003-01-0745. doi: 10.4271/2003-01-0745.

[4] A. J. Torregrosa, A. Broatch, A. García, L. F. Mónico, Sensitivity of combustion noise and NOx and soot emissions to pilot injection in PCCI diesel engines, Applied Energy 104 (0) (2013) 149-157. doi:http: //dx.doi.org/10.1016/j.apenergy.2012.11.040.

[5] Y. Takeda, N. Keiichi, N. Keiichi, Emission characteristics of premixed lean Diesel combustion with extremely early staged fuel injection, in: SAE Technical Paper, Vol. 961163. doi:10.4271/961163.

[6] W. L. Hardy, R. D. Reitz, A study of the effects of high EGR, high equivalence ratio, and mixing time on emissions levels in a heavy-duty diesel engine for PCCI combustion, in: SAE Technical Paper, Vol. 2006-010026. doi:10.4271/2006-01-0026.

[7] R. Hanson, D. Splitter, R. Reitz, Operating a heavy-duty direct-injection compression-ignition engine with gasoline for low emissions, in: SAE Technical Paper, Vol. 2009-01-1442. doi:10.4271/2009-01-1442.
[8] V. Manente, B. Johansson, P. Tunestal, W. Cannella, Effects of different type of gasoline fuels on heavy duty partially premixed combustion, SAE International Journal of Engines 2 (2) (2010) 71-88. doi:10.4271/ 2009-01-2668.

[9] O. Laget, C. Ternel, J. Thiriot, S. Charmasson, P. Tribotté, F. Vidal, Preliminary design of a two-stroke uniflow diesel engine for passenger car, in: SAE Technical Paper, Vol. 2013-01-1719. doi:10.4271/ 2013-01-1719.

[10] B. Yang, L. Wang, L. Ning, K. Zeng, Effects of pilot injection timing on the combustion noise and particle emissions of a diesel/natural gas dualfuel engine at low load, Applied Thermal Engineering 102 (2016) 822 - 828. doi:http://dx.doi.org/10.1016/j.applthermaleng. 2016.03.126.

[11] J. Benajes, R. Novella, D. De Lima, P. Tribotte, N. Quechon, P. Obernesser, V. Dugue, Analysis of the combustion process, pollutant emissions and efficiency of an innovative 2-stroke HSDI engine designed for automotive applications, Applied Thermal Engineering 58 (2013) 181-193. doi:http://dx.doi.org/10.1016/j.applthermaleng. 2013.03.050.

[12] J. Benajes, S. Molina, R. Novella, D. De Lima, Implementation of the partially premixed combustion concept in a 2-stroke HSDI diesel engine fueled with gasoline, Applied Energy 122 (0) (2014) 94-111. doi : http: $/ / \mathrm{dx}$.doi.org/10.1016/j. apenergy.2014.02.013.

[13] J. Benajes, R. Novella, D. De Lima, P. Tribotte, Investigation on multiple injection strategies for gasoline PPC operation in a newly designed 2-stroke HSDI compression ignition engine, Vol. 8, 2015, pp. 758-774. doi: 10.4271/2015-01-0830.

[14] J. Benajes, J. Martín, R. Novella, K. Thein, Understanding the performance of the multiple injection gasoline partially premixed combustion concept implemented in a 2-stroke high speed direct injection compression ignition engine, Applied Energy 161 (2016) 465 - 475. doi : http: $/ /$ dx.doi.org/10.1016/j.apenergy.2015.10.034.

[15] A. J. Torregrosa, A. Broatch, R. Novella, L. F. Mónico, Suitability analysis of advanced diesel combustion concepts for emissions and noise control, Energy 36 (2) (2011) 825-838. doi:http://dx.doi.org/10. 1016/j. energy . 2010.12.032.

[16] A. J. Torregrosa, A. Broatch, J. Martín, L. Monelletta, Combustion noise level assessment in direct injection diesel engines by means of in-cylinder pressure components, Measurement Science and Technology 18 (7) (2007) 2131-2142. doi : doi : 10 .1088/0957-0233/18/7/045.

[17] F. Payri, A. Broatch, X. Margot, L. Monelletta, Sound quality assessment of diesel combustion noise using in-cylinder pressure components, Measurement Science and Technology 20 (1) (2009) 01-12. doi : doi: 10.1088/0957-0233/20/1/015107.

[18] H. Liu, J. Zhang, P. Guo, F. Bi, H. Yu, G. Ni, Sound quality prediction for engine-radiated noise, Mechanical Systems and Signal Processing 56-57 (0) (2015) 277-287. doi:http://dx.doi.org/10.1016/ j.ymssp. 2014.10.005.

[19] K. Ohta, Y. Irie, K. Yamamoto, H. Ishikawa, Piston slap induced noise and vibration of internal combustion engines (1st report, theoretical analysis and simulation), SAE Technical Paper 870990. doi:10.4271/870990.

[20] S. H. Cho, S. T. Ahn, Y. H. Kim, A simple model to estimate the impact force induced by piston slap, Journal of Sound and Vibration 255 (2) (2002) 229-242. doi:http://dx.doi.org/10.1006/jsvi.2001. 4152.

[21] F. Payri, A. Broatch, B. Tormos, V. Marant, New methodology for incylinder pressure analysis in direct injection diesel engines-application to combustion noise, Measurement Science and Technology 16 (2) (2005) 
540-547. doi:doi:10.1088/0957-0233/16/2/029.

[22] A. Broatch, X. Margot, R. Novella, J. Gomez-Soriano, Combustion noise analysis of partially premixed combustion concept using gasoline fuel in a 2-stroke engine, Energy 107 (2016) 612 - 624. doi : http://dx.doi. org/10.1016/j.energy.2016.04.045

[23] R. Hickling, D. A. Feldmaier, S. H. Sung, Knock-induced cavity resonances in open chamber Diesel engines, Acoustical Society of America 65 (5) (1979) 1474-1479. doi : http://dx.doi.org/10.1121/1. 382910.

[24] A. Broatch, C. Guardiola, B. Pla, P. Bares, A direct transform for determining the trapped mass on an internal combustion engine based on the in-cylinder pressure resonance phenomenon, Mechanical Systems and Signal Processing 62-63 (2015) 480 - 489. doi : http://dx.doi .org/ 10.1016/j.ymssp. 2015.02.023.

[25] A. J. Torregrosa, A. Broatch, X. Margot, V. Marant, Combustion chamber resonances in direct injection automotive Diesel engines: a numerical approach, International Journal of Engine Research 5 (1) (2003) 83-91. doi : 10.1243/146808704772914264.

[26] A. Broatch, X. Margot, A. Gil, C. Donayre, Computational study of the sensitivity to ignition characteristics of the resonance in DI diesel engine combustion chambers, Engineering Computations 24 (1) (2007) 77-96. doi:http://dx.doi.org/10.1108/02644400710718583.

[27] J. Benajes, R. Novella, D. De Lima, P. Tribotté, Analysis of combustion concepts in a newly designed two-stroke high-speed direct injection compression ignition engine, International Journal of Engine Researchdoi:10.1177/1468087414562867.

[28] P. Tribotte, F. Ravet, V. Dugue, P. Obernesser, N. Quechon, J. Benajes, R. Novella, D. De Lima, Two strokes diesel engine - promising solution to reduce $\mathrm{CO} 2$ emissions, Procedia - Social and Behavioral Sciences 48 (2012) 2295-2314. doi:http://dx.doi.org/10.1016/j.sbspro. 2012.06 .1202$.

[29] R. Payri, F. J. Salvador, J. Gimeno, G. Bracho, A new methodology for correcting the signal cumulative phenomenon on injection rate measurements, Experimental Techniques 32 (1) (2008) 46-49. doi : 10.1111/j . 1747-1567.2007.00188.x.

[30] F. Ihlenburg, The medium-frequency range in computational acoustics: Practical and numerical aspects, Journal of Computational Acoustics 11 (02) (2003) 175-193. doi:http://dx.doi.org/10.1142/ S0218396X03001900.

[31] M. Lapuerta, O. Armas, J. J. Hernández, Diagnosis of DI diesel combustion from in-cylinder pressure signal by estimation of mean thermodynamic properties of the gas, Applied Thermal Engineering 19 (5) (1999) 513-529. doi:http://dx.doi.org/10.1016/ S1359-4311 (98)00075-1.

[32] F. Payri, S. Molina, J. Martín, O. Armas, Influence of measurement errors and estimated parameters on combustion diagnosis, Applied Thermal Engineering 26 (2-3) (2006) 226-236.

[33] A. Torregrosa, P. Olmeda, B. Degraeuwe, M. Reyes, A concise wall temperature model for DI diesel engines, Applied Thermal Engineering 26 (11-12) (2006) 1320-1327. doi:http://dx.doi.org/10.1016/ j.applthermaleng.2005.10.021.

[34] Y. Ren, R. B. Randall, B. E. Milton, Influence of the resonant frequency on the control of knock in diesel engines, Proceedings of the Institution of Mechanical Engineers 213 (Part D) (1999) 127-133. doi:https : //doi.org/10.1243/0954407991526748.

[35] V. Yakhot, S. Orszag, Renormalization group analysis of turbulence., Journal of Scientific Computing 1 (1) (1986) 3-51. doi : doi:10.1007/ BF01061452.

[36] C. Angelberger, T. Poinsot, B. Delhay, Improving near-wall combustion and wall heat transfer modeling in si engine computations, in: SAE Technical Paper, SAE International, 1997. doi : 10.4271/972881. URL http://dx.doi.org/10.4271/972881

[37] J. K. Dukowicz, A particle-fluid numerical model for liquid sprays, Journal of Computational Physics 35 (2) (1980) 229 - 253. doi:http: //dx.doi.org/10.1016/0021-9991(80)90087-X.

[38] R. D. Reitz, J. C. Beale, Modeling spray atomization with the kelvinhelmholtz/rayleigh-taylor hybrid model, Atomization and Sprays 9 (6) (1999) 623-650.

[39] R. Payri, J. García, F. Salvador, J. Gimeno, Using spray momentum flux measurements to understand the influence of diesel nozzle geometry on spray characteristics, Fuel 84 (5) (2005) 551-561. doi:http://dx. doi.org/10.1016/j.fuel.2004.10.009.

[40] J. Brakora, R. D. Reitz, A comprehensive combustion model for biodiesel-fueled engine simulations, in: SAE Technical Paper, SAE International, 2013. doi : 10.4271/2013-01-1099.

[41] L. Stanković, J. F. Böhme, Time-frequency analysis of multiple resonances in combustion engine signals, Signal Processing 79 (1) (1999) 1528. doi : http://dx.doi.org/10.1016/S0165-1684(99)00077-8.

[42] J. M. Desantes, A. J. Torregrosa, A. Broatch, Wavelet transform applied to combustion noise analysis in high-speed DI Diesel engines, SAE Technical Paper 2001-01-1545. doi:10.4271/2001-01-1545.

[43] J. Chang, G. Kalghatgi, A. Amer, Y. Viollet, Enabling high efficiency direct injection engine with naphtha fuel through partially premixed charge compression ignition combustion, in: SAE Technical Paper, Vol. 201201-0677. doi : 10.4271/2012-01-0677.

[44] D. Anderton, Relation between combustion system and engine noise, Vol. 790270, 1979. doi:10.4271/790270.

[45] A. E. W. Austen, T. Priede, Origins of Diesel engine noise, in: SAE Technical Paper, SAE International, 1959. doi : 10.4271/590127.

[46] M. S. Khan, Ö. Johansson, W. Lindberg, U. Sundbäck, Annoyance of idling diesel engine noise evaluated by multivariate analysis, Noise Control Engineering Journal 43 (6) (1995) 197-207. doi:10.3397/1. 2828380.

[47] A. J. Shahlari, C. Hocking, E. Kurtz, J. Ghandhi, Comparison of compression ignition engine noise metrics in low-temperature combustion regimes, Vol. 6, SAE International, 2013, pp. 541-552. doi : 10.4271/ 2013-01-1659.

[48] M. Wissink, Z. Wang, D. Splitter, A. Shahlari, R. D. Reitz, Investigation of pressure oscillation modes and audible noise in RCCI, HCCI, and CDC, in: SAE Technical Paper, Vol. 2013-01-1652, SAE International, 2013. doi : $10.4271 / 2013-01-1652$.

\begin{tabular}{|c|c|}
\hline Nomenc & lature \\
\hline$S u b-a$ & d Superscripts \\
\hline$c y l$ & related to cylinder \\
\hline ign. & related to ignition \\
\hline $\max$ & maximum value \\
\hline norm & normalised value \\
\hline res & related to resonance phenomena \\
\hline trans & related to transducer location \\
\hline List of & abbreviations \\
\hline aTDC & after Top Dead Center \\
\hline cad & crank angle degree \\
\hline $\mathrm{EVC}$ & exhaust valve closing (angle) \\
\hline EVO & exhaust valve opening (angle) \\
\hline IMEP & indicated mean effective pressure \\
\hline IVC & intake valve closing (angle) \\
\hline IVO & intake valve opening (angle) \\
\hline LHV & lower heating value \\
\hline SPL & sound pressure level \\
\hline
\end{tabular}

\section{List of Figures}

1 Computational domain and mesh characterization of the engine architecture at different calculation phases. . . . . . . . . . . .

2 Comparison between measured and CFD calculated, measurements dispersion is represented by their standard deviation (SD). a) In-cylinder pressure and RoHR traces, b) Pressure spectra traces, c) to f) CPL, ON, $(d p / d \alpha)_{\text {max }}$ and $\mathrm{E}_{\text {res }}^{\text {trans }}$ parameters trends. . . . . . . . . . . 
3 Comparison of the in-cylinder pressure and RoHR traces. a) Included spray angle study, b) Number of injector nozzles study. . . . . . . . . . .

4 Effects of the included spray angle and number of injector nozzles. a) Cylinder pressure level, b) Overall noise, c) Maximum pressure timederivative, d) Energy of resonance. . . . . . . .

6 Comparison of the in-cylinder pressure spectra trends. The pressure spectrum averaged over all monitors distributed in the domain is plotted with its standard deviation (SD). a) Test 05 and 06, b) Test 04 and $07 \ldots . . . . . . . . .$.

5 Results of the combustion process analysis for tests 05, 06, 04 and 07. a) RoHR contours along equivalence ratio and crank angle degree, b) RoHR contours along the radial dimension of the cylinder engine, c) Histogram of RoHR along the radial dimension of the cylinder engine at the start of combustion (SoeP).

\section{List of Tables}

1 Engine specifications and injection system characterization .................. 3

2 Fuel properties ............ 3

3 Main engine settings for all operation points evaluated in the validation procedure. . . . . 6

4 Injector configuration for all simulations analysed in this investigation. . . . . . . . 7

5 Combustion characterisation parameters (SoeP, $(d p / d \alpha)_{\max }$ and $\left.R^{\text {norm }}\right)$ in tests $04,05,06$ and $07 \quad 11$ 